DOI: $10.17516 / 2782-2214-0027$

УДК 640.41

\title{
ASSESSMENT OF THE COMPETITIVENESS OF 3-STAR HOTELS IN KRASNOYARSK
}

\section{Olga A. Yabrova*, Tatyana L. Kamoza, Tatyana N. Safronova, Alyona A. Yakusheva} Siberian Federal University, Krasnoyarsk, Russian Federation

\begin{abstract}
The article is devoted to assessing the competitiveness of 3-star hotels on the example of Krasnoyarsk. Today Krasnoyarsk is one of the centers of attraction for domestic tourism, both in the region and in the Russian Federation. Residents of the Krasnoyarsk region and other regions of Russia form about $90 \%$ of the tourist flow. Today Krasnoyarsk is one of the most beautiful cities in the country, a modern industrial city with unique architecture. The number of collective accommodation facilities for 2020 amounted to 174 units for 11305 places. Currently, 3-star hotels are particularly popular among foreign and domestic tourists. To assess the competitiveness of accommodation facilities, the methodology of "analysis of four indicators", which is used in marketing, was selected and adapted to assess the competitiveness of the enterprise. The main factors for assessing competitiveness were: "location", "pricing policy", "service level". Based on the assessment, hotels with the highest level of competitiveness in the hotel market of Krasnoyarsk were identified. The highest rating was taken by the hotels: Krasnoyarsk (19.8), Snowy Owl (19.36), Ibis Krasnoyarsk Center (18.72). Hotels have a low rating: gArage (14.96), Yakhont (14.16), Dvorik (14.4).
\end{abstract}

Keywords: Krasnoyarsk hotel market, 3-star hotels, main factors of competitiveness, rating.

Citation: Yabrova, O. A., Kamoza, T. L., Safronova, T. N., Yakusheva, A. A. (2021). Assessment of the competitiveness of 3-star hotels in Krasnoyarsk. Trade, service, food industry. Vol. 1(3). Pp. 274-282.

\section{ОЦЕНКА КОНКУРЕНТОСПОСОБНОСТИ ГОСТИНИЦ КАТЕГОРИИ «З ЗВЕЗДЫ» ГОРОДА КРАСНОЯРСКА \\ Ольга Александровна Яброва*, Татьяна Леонтьевна Камоза, Татьяна Николаевна Сафронова, Алена Александровна Якушева ФГАОУ ВО «Сибирский федеральный университет» Красноярск, Российская Федерация}

\begin{abstract}
Аннотация. Статья посвящена оценке конкурентоспособности гостиниц категории «3 звезды» на примере Красноярска. Сегодня этот город является одним из центров притяжения для внутреннего туризма самого края и Российской Федерации в целом. Жители Красноярского края и других регионов России формируют около 90 \% туристского потока. Красноярск - один из красивейших городов страны, современный индустриальный центр с уникальной архитектурой. Численность коллективных средств размещения на 2020 год составила 174 ед. на 11305 мест. В настоящее время особой популярностью среди иностранных и отечественных туристов пользуются гостиницы категории «3 звезды». Для оценки конкурентоспособности средств размещения была выбрана и адаптирована методика «Анализ четырех показателей», которая
\end{abstract}

\footnotetext{
(C) Siberian Federal University. All rights reserved

*Corresponding author E-mail address: advanceoa@yandex.ru

ORCID ID: 0000-0001-6464-6837 (Safronova)
} 
используется в маркетинге с целью изучения конкурентоспособности предприятия. Основными факторами оценки здесь выступили следующие: «месторасположение», «ценовая политика», «уровень сервиса». На основе проведенного исследования были выявлены гостиницы с наибольшим уровнем конкурентоспособности на гостиничном рынке г. Красноярска. Самый высокий рейтинг заняли гостиницы «Красноярск» $(19,8)$, «Снежная Сова» $(19,36)$, «Ibis Красноярск Центр» $(18,72)$. Низкий рейтинг у гостиниц «Гараж» $(14,96)$, «Яхонт» $(14,16)$, «Дворик» $(14,4)$.

Ключевые слова: гостиничный рынок г. Красноярска, гостиницы категории «3 звезды», основные факторы конкурентоспособности, рейтинг.

Введение. Основной целью для любого предприятия в условиях рыночной экономики является сохранение или расширение занимаемых позиций на рынке, а также стабильное получение прибыли или ее рост [1-3]. Усиление глобализации мировой экономики, увеличение ее темпов и масштабов вызывают рост конкуренции на внешнем и внутреннем рынке. Под конкурентоспособностью гостиничных предприятий понимают реальную и потенциальную способность оказывать услуги, которые по своим характеристикам более привлекательны, чем услуги других организаций. Рост финансово-экономических показателей гостиничного предприятия обеспечивается постоянным совершенствованием конкурентоспособности, который, в свою очередь, обусловлен максимальным удовлетворением потребностей гостей, повышением результативности работы [2-3].

Для оценки конкурентоспособности гостиничного предприятия используют некоторые численные показатели. Они характеризуют степень его устойчивости, способность оказывать гостиничную услугу, пользующуюся спросом и обеспечивающую предприятию получение стабильных результатов деятельности. Наиболее важные конкурентные преимущества гостиничных предприятий характеризуются состоянием материально-технической базы, месторасположением, уровнем качества обслуживания, спектром предоставляемых услуг, узнаваемостью торговой марки, уровнем стоимости услуг и др. [1-3].

Красноярск - административный центр Красноярского края и центр ВосточноСибирского экономического района [4]. Это один из красивейших городов страны, столица мастеровых, талантливых людей Сибири. Численность населения на 1 января 2020 года составляла 1094548 человек [5]. Расположение города на реке Енисей, крупной водной транспортной магистрали, делает его воротами для выхода нескольких регионов Центральной Сибири через Северный морской путь на мировой рынок. Красноярск имеет опыт проведения XXIX Всемирной зимней универсиады 2019 года [4].

Видами туризма, формирующими значительные туристские потоки в Красноярске, являются: деловой, активный, культурно-познавательный. Численность коллективных средств размещения на 2020 год составила 174 ед. на 11305 мест [5]. В настоящее время особой популярностью у иностранных и отечественных туристов пользуются гостиницы категории «3 звезды». Люди хотят получить комфортные условия проживания и качественное обслуживание за небольшие деньги. Такие гостиницы имеют высокий уровень конкурентоспособности. Они не отстают по качеству предоставляемых услуг от отелей более высоких категорией, но входят в меньший ценовой сегмент. Сегодня в Красноярске функционирует 18 гостиниц категории «3 звезды», но не каждая из них пользуется достаточным спросом. На выбор гостиницы влияют месторасположение в городе, уровень сервиса, состояние номеров, перечень оказываемых дополнительных услуг и многие другие факторы. 
Материалы и методы. Целью исследования стала оценка конкурентоспособности гостиниц категории «3 звезды». В качестве объектов исследования были определены гостиничные предприятия указанной категории в городе Красноярске. Для достижения цели были использованы следующие методы: сбор информации путем регистрации фактов и явлений в естественных условиях; сопоставление двух и более объектов, выделение в них общего и различного; экспертные оценки. Оценка конкурентоспособности гостиниц категории «3 звезды» города Красноярска, проведена с использованием информации официального сайта интернет-бронирования отелей Booking.com [6], а также результатов собственных наблюдений авторов.

Для оценки конкурентоспособности средств размещения была выбрана и адаптирована методика «Анализ четырех показателей» [1-2], которая имеет следующую формулу:

$$
K_{n}=\frac{\sum_{i=1}^{n} \mathrm{~b}_{i j} / n}{5} \times a_{j},
$$

где $\mathrm{K}_{\mathrm{n}}$ - конкурентоспособность услуги; $\boldsymbol{b}_{\mathrm{ij}}$ - экспертная оценка $\mathrm{i}-\mathrm{M}$ экспертом $\mathrm{j}$-го критерия конкурентоспособности услуги; $\mathrm{a}_{\mathrm{j}}$ - весомость ј-го критерия (от 4 до 1); каждый критерий имеет вес, максимальная оценка критерия - 5.

Основными критериями оценки фактора «месторасположение» выступали:

- удобная транспортная развязка вблизи гостиницы;

- развитая инфраструктура района (наличие крупных федеральных компаний/заводов, спортивных сооружений, парков, объектов культуры);

- бесплатная парковка (наличие возможности высадить гостя из машины перед входом в отель);

- доступность главных достопримечательностей города.

Критерии фактора «ценовая политика» следующие:

- имидж торговой марки;

- стоимость номера;

- рейтинг на сайте Booking.com;

- перечень дополнительных услуг (наличие тренажерного зала, конференцзала, библиотеки и т. д.).

Основными критериями оценки фактора «уровень сервиса» выступали: персонала);

- качество обслуживания (вежливость, компетентность и отзывчивость

- наличие услуги room-service;

- комплектация номера (оснащение кондиционером, чайником, феном, косметическими принадлежностями и т. д.);

- ассортимент предоставляемых услуг.

Обсуждение. Структура гостиничного рынка г. Красноярска представлена в основном сетевыми гостиницами («AMAKS Hotels\&Resorts», «Ibis Hotel», «Novotel Hotels», «Hilton Hotels \& Resorts») и частными отелями [7].

Расположение гостиницы - важное конкурентное преимущество. В индустриальных городах наибольшим спросом пользуются гостиницы, находящиеся вблизи деловых центров и транспортных развязок. Распределение гостиниц категории «3 звезды» по районам г. Красноярска представлено на рис. 1. 


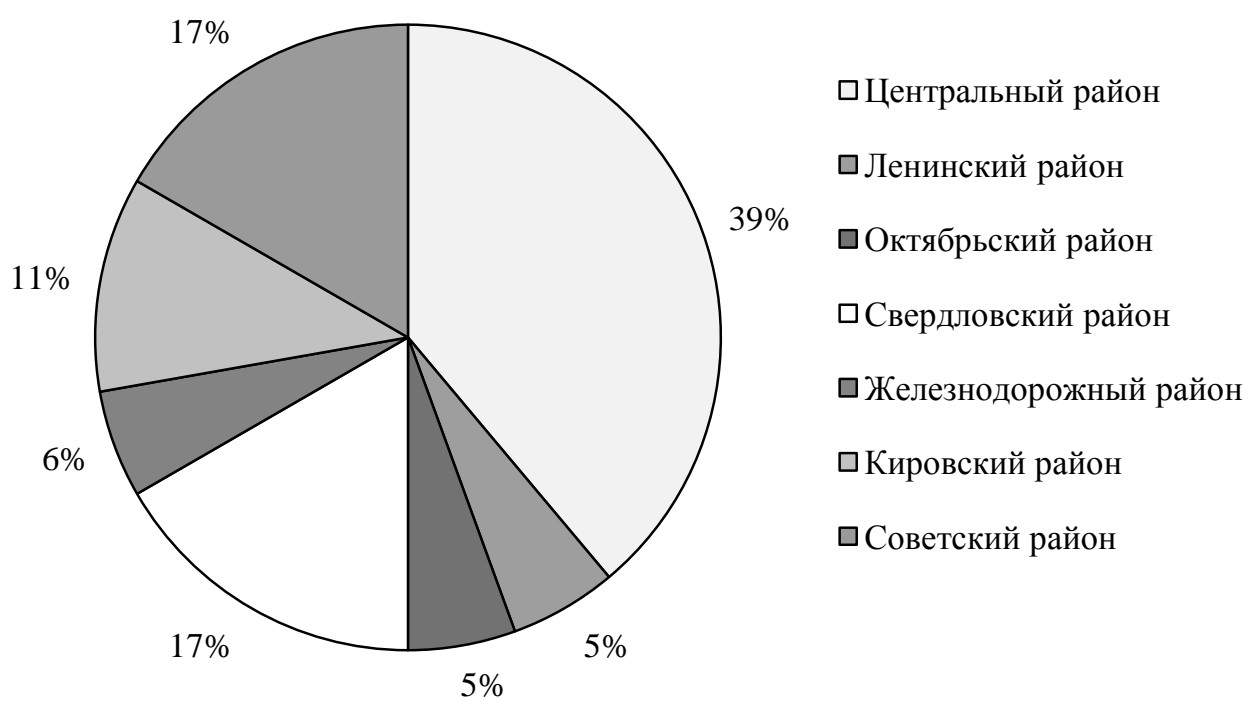

Рисунок 1. Распределение гостиниц категории «3 звезды» по районам г. Красноярска Figure 1. Distribution of 3-star hotels by districts of Krasnoyarsk

По данным диаграммы можно сделать вывод о том, что самым популярным является Центральный район г. Красноярска. Здесь сосредоточено большинство гостиниц категории «3 звезды» $(39$ \%). Район привлекателен для туристов своей инфраструктурой и способами проведения досуга.

Положительный имидж или репутация гостиницы напрямую влияют на ее конкурентные преимущества. По рейтингу сайта booking.com анализируемые предприятия разместились в следующем порядке (рис. 2) [6].

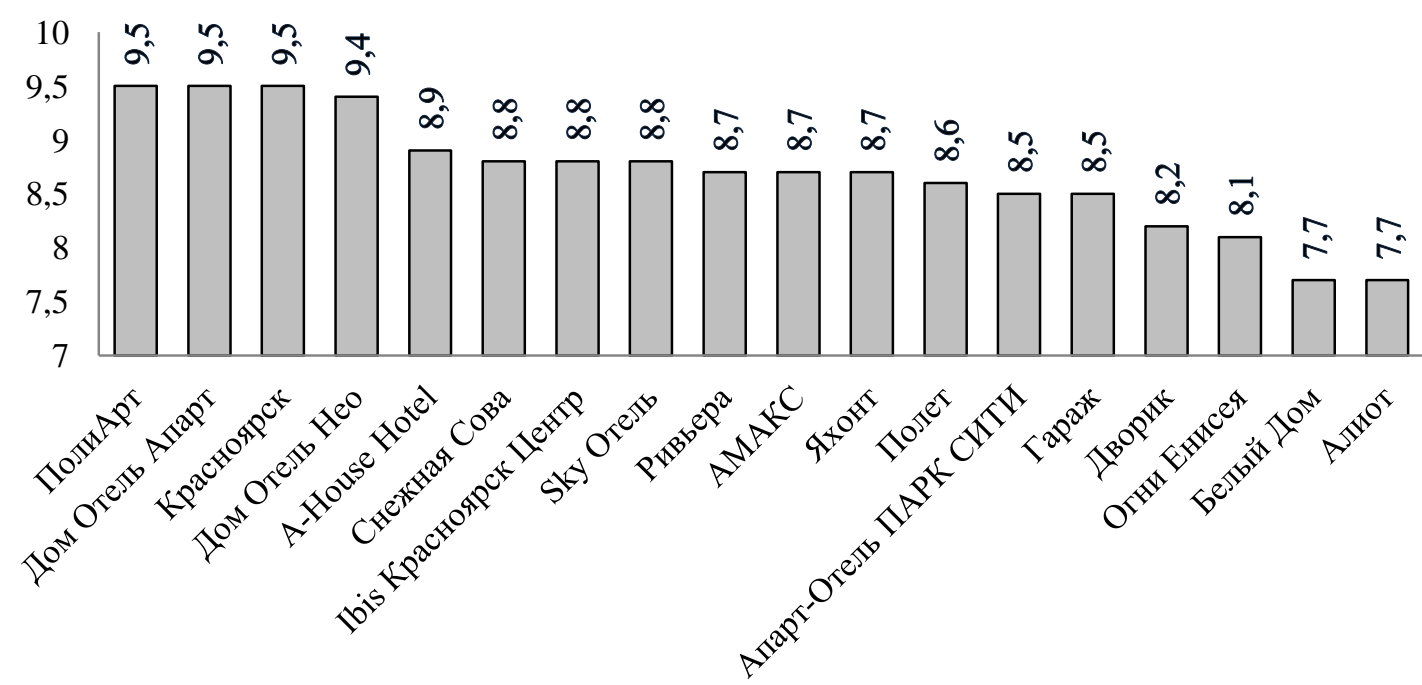

Рисунок 2. Рейтинг гостиниц категории «3 звезды» по версии сайта booking.com

Figure 2. Rating of 3-star hotels according to the website version booking.com

Гостиницы «ПолиАрт», «Дом Отель Апарт» и «Красноярск» имеют самый высокий рейтинг. Данные отели популярны среди гостей, об этом можно судить по отзывам на сайте booking.com. Удобное месторасположение, вкусная еда, отличный сервис, развитая инфраструктура и многие другие факторы делают эти гостиницы наиболее привлекательными. 
Конкурентным преимуществом гостиничного предприятия также являются предметные и функциональные стороны - площадь и оснащенность гостиничных номеров, общих помещений, техническая обеспеченность и т.д. На гостиничном рынке г. Красноярска категории «3 звезды» представлены как новые гостиницы, сроком эксплуатации до трех лет, так и старые, которые были открыты еще в прошлом веке. Анализ номерного фонда гостиниц и его стоимость представлены в табл. 1.

Таблица 1. Номерной фонд гостиниц категории «3 звезды» и их стоимость Table 1 . The number of rooms of 3 -star hotels and their cost

\begin{tabular}{|l|c|c|c|}
\hline \multicolumn{1}{|c|}{ Название гостиницы } & $\begin{array}{c}\text { Года открытия } \\
\text { гостиницы }\end{array}$ & $\begin{array}{c}\text { Номерной фонд, } \\
\text { (ед.) }\end{array}$ & $\begin{array}{c}\text { Минимальная } \\
\text { стоимость номера, } \\
\text { (руб./сутки) }\end{array}$ \\
\hline "АМАКС Сити Отель" & 2002 & 295 & 2450 \\
\hline "Красноярск" & 1976 & 249 & 3500 \\
\hline "Огни Енисея" & 1965 & 140 & 3200 \\
\hline "Іьіз Красноярск Центр" & 2015 & 116 & 3700 \\
\hline "Снежная Сова" & 2016 & 110 & 2550 \\
\hline "Полет" & 2007 & 94 & 2500 \\
\hline "Апарт Отель ПАРК СИТИ" & 2017 & 93 & 3050 \\
\hline "Дом Отель Нео" & 2012 & 63 & 2300 \\
\hline "Яхонт" & 2001 & 58 & 1600 \\
\hline "Белый Дом" & 2013 & 30 & 2000 \\
\hline "Дворик" & 2017 & 30 & 2500 \\
\hline "Гараж" & 2010 & 27 & 1500 \\
\hline "Ривьера" & 2011 & 20 & 3300 \\
\hline "Алиот" & 2006 & 17 & 2500 \\
\hline "ПолиАрт" & 2017 & 14 & 3000 \\
\hline "А-Ноизе Нотеl" & 2000 & 14 & 3550 \\
\hline "Skу Отель" & 2011 & 12 & \\
\hline "Дом Отель Апарт" & 2008 & 11 & \\
\hline
\end{tabular}

Основываясь на принятой во всем мире классификации гостиниц по количеству номерного фонда, гостиницы «АМАКС Сити Отель» и «Красноярск» - крупные отели. Все остальные считаются малыми. Самым дорогим средством размещения является гостиница «Ibis Красноярск Центр», так как она расположена в центральной части города и принадлежит к крупной гостиничной сети. Самое бюджетное место гостиница «Алиот», при этом она имеет все необходимые удобства для комфортного отдыха.

Для любого гостя важны качество и количество предоставляемых гостиницей дополнительных услуг. Проанализировав разнообразие таких услуг в гостиницах рассматриваемой категории, можно сделать вывод, что наибольшее их число представлено предприятиями «Красноярск», «Огни Енисея», «Ibis Красноярск Центр», наименьшее - «Апарт Отель ПАРК СИТИ», «ЯхонТ».

Полученные результаты. На основе разработанной методики оценки конкурентных преимуществ гостиниц и экспертной оценки всех гостиниц категории «3 звезды» г. Красноярска, были проведены расчеты по ранее заданной формуле (1).

По оценкам экспертов фактора «месторасположение» гостиницы ранжированы в следующем порядке (рис. 3). 


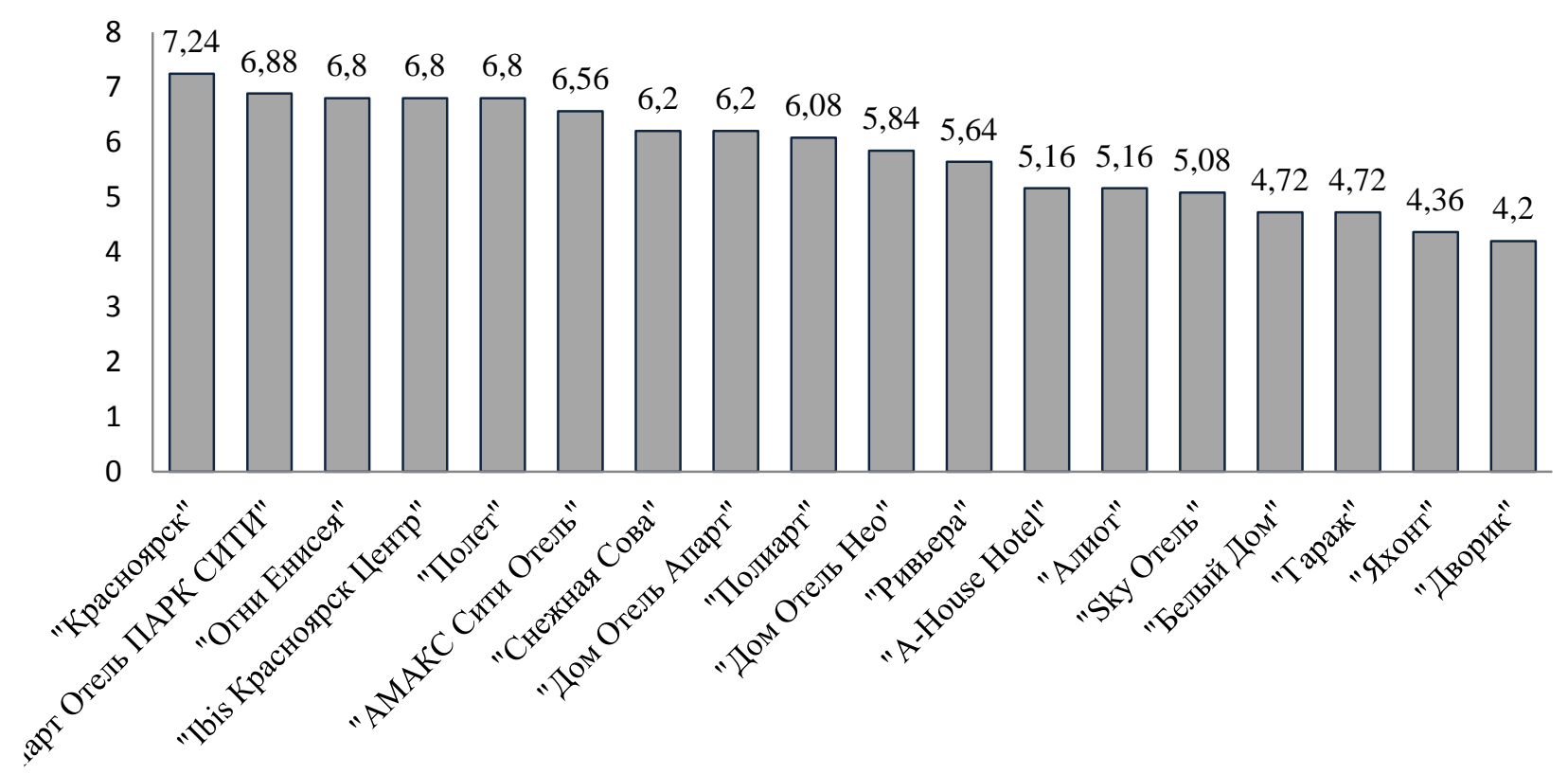

Рисунок 3. Рейтинг гостиниц категории «3 звезды» г. Красноярска по фактору «месторасположение»

Figure 3. Rating of 3-star hotels in Krasnoyarsk by the "location" factor

По данным представленного рейтинга можно сделать вывод о том, что гостиницы «Красноярск» $(7,24)$ и «Апарт Отель ПАРК СИТИ» $(6,88)$ имеют самое выгодное месторасположение в городе. Это позволяет говорить о том, что данные гостиницы пользуются популярностью среди гостей и жителей города, благодаря тому, что первая расположена в самом центре города, вблизи культурных и исторических объектов, а «Апарт Отель ПАРК СИТИ» находится в одном из самым популярных районов города «Взлетка», вблизи живописной набережной реки Енисей.

Самым неконкурентоспособным объектом по данному фактору выступает гостиница «Дворик» $(4,2)$. Ее месторасположение не совсем подходит для отдыха, так как здание гостиницы расположено у оживленной дороги и железнодорожных путей.

По оценкам экспертов фактора «ценовая политика» гостиницы расположились в следующем порядке (рис. 4).

По данным представленного рейтинга можно выделить гостиницы «Снежная Сова» (6,48), «A-House Hotel» $(6,4)$ и «Красноярск» $(6,36)$ как самые конкурентоспособные по фактору «ценовая политика». Данные гостиницы отвечают требованиям гостей к комфорту и имеют относительно невысокую стоимость номеров. Остальные гостиницы, по полученным оценкам, находятся на уровне выше среднего, что позволяет говорить о том, что гостиницы категории «3 звезды» г. Красноярска оснащены всем необходимым для проживания и отвечают существующим нормативным требованиям к данной группе предприятий.

По оценкам экспертов фактора «уровень сервиса» гостиницы разместились в следующем порядке (рис. 5).

По данным представленного рейтинга можно сделать вывод о том, что гостиница «Снежная Сова» $(6,68)$ соответствует самому высокому уровню предоставляемого сервиса. Данная гостиница имеет широкий перечень предоставляемых услуг, максимальную комплектацию всех номеров, услугу roomservice на протяжении всего дня и грамотно обученный персонал. 


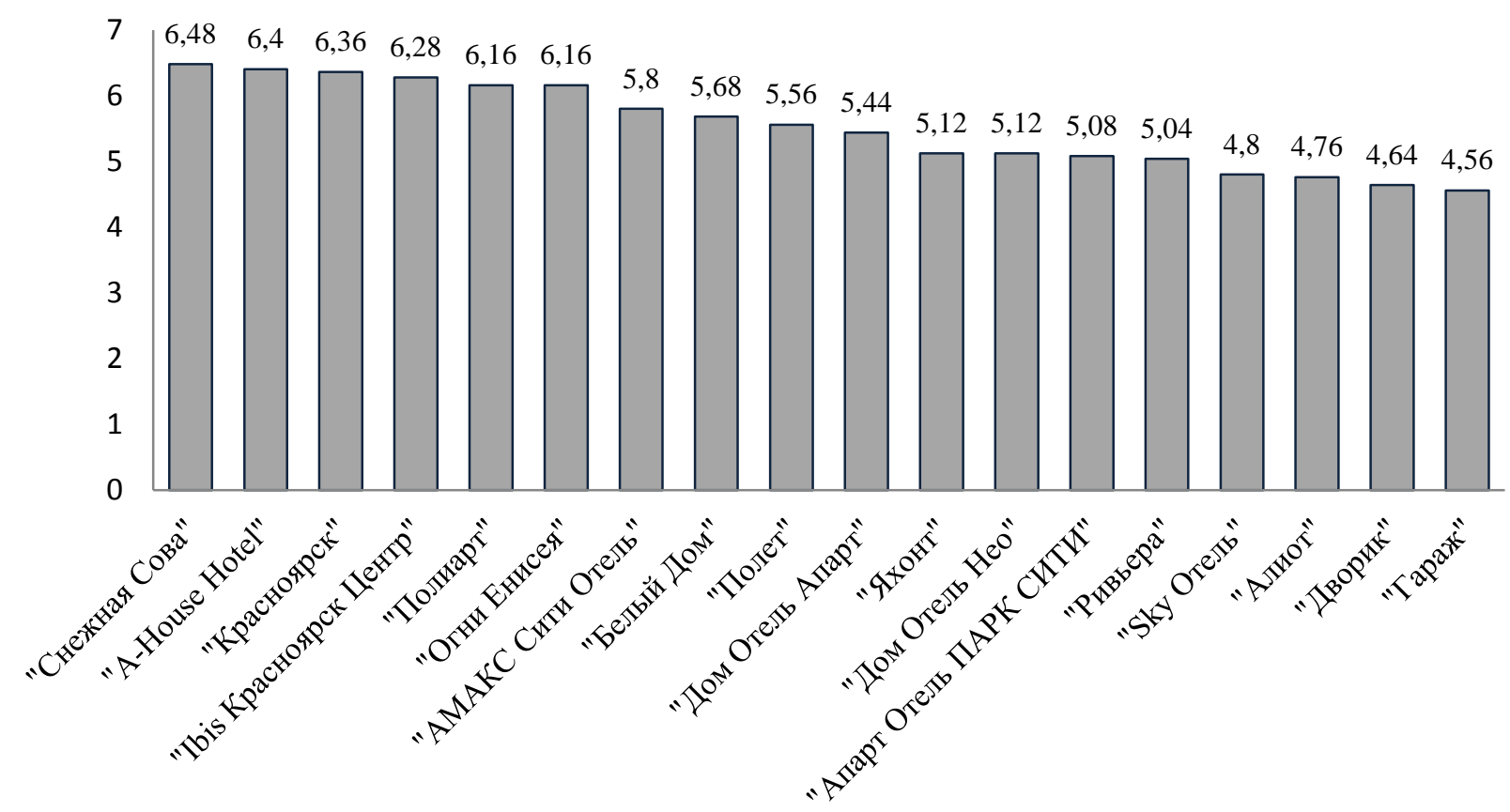

Рисунок 4. Рейтинг гостиниц категории «3 звезды» г. Красноярска по фактору «ценовая политика»

Figure 4. Rating of 3-star hotels in Krasnoyarsk by the "pricing policy" factor

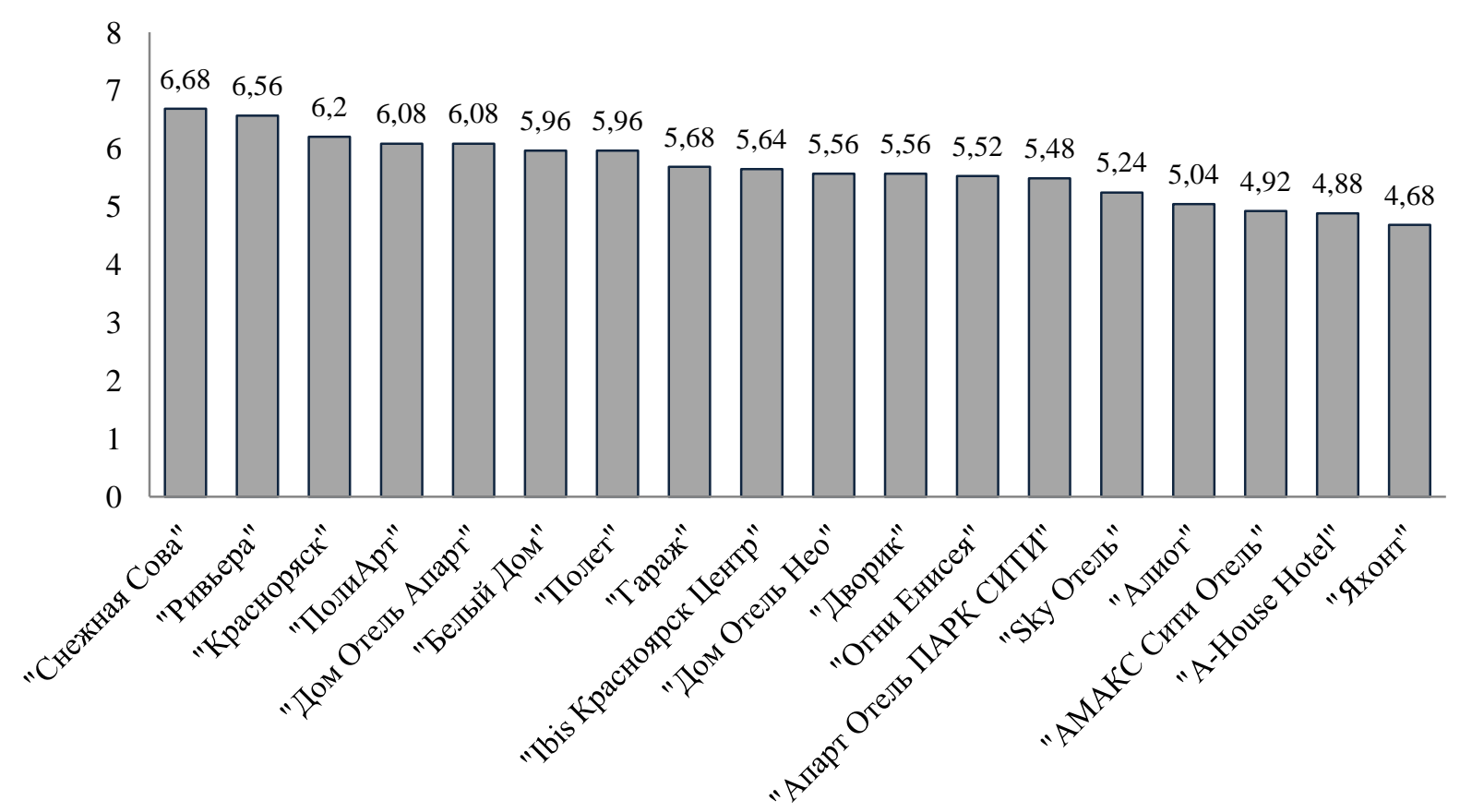

Рисунок 5. Рейтинг гостиниц категории «3 звезды» г. Красноярска по фактору «уровень сервиса»

Figure 5. Rating of 3-star hotels in Krasnoyarsk by the "service level" factor

Практически все гостиницы города имеют хороший сервис, но есть недостатки, над которыми необходимо работать для улучшения качества обслуживания и привлечения новых клиентов. 
На основе анализа всех оцениваемых факторов можно сделать вывод о том, что не все гостиницы категории «3 звезды» г. Красноярска отвечают требованиям гостей и способны на должном уровне конкурировать с другими гостиницами на данном рынке услуг г. Красноярска (рис. 6). Самый высокий рейтинг заняли гостиницы «Красноярск» $(19,8)$, «Снежная Сова» $(19,36)$, «Ibis Красноярск Центр» $(18,72)$, а низкий - «Гараж» $(14,96)$, «Яхонт» $(14,16)$, «Дворик» $(14,4)$.

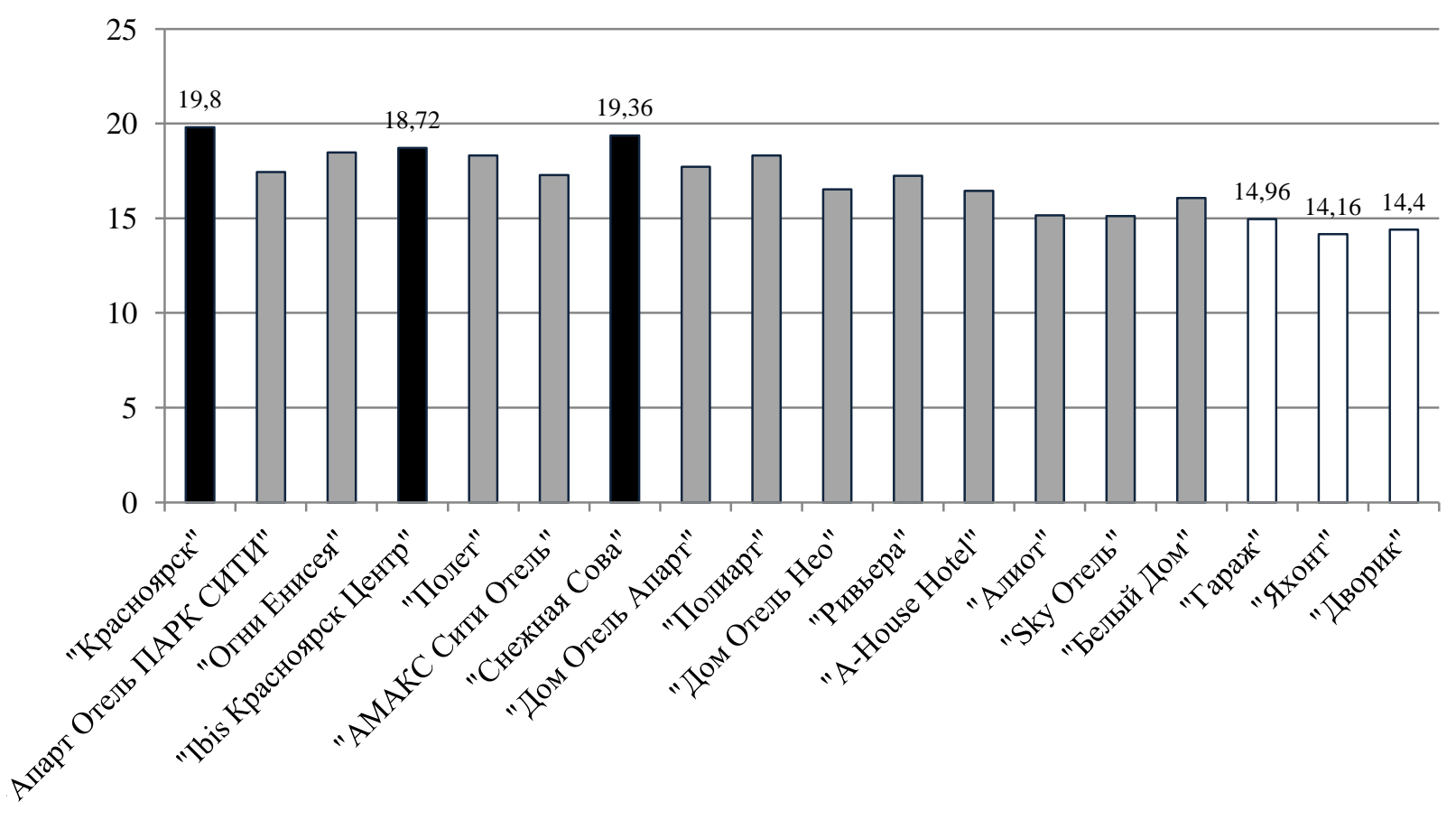

Рисунок 6. Рейтинг конкурентоспособности гостиниц категории «3 звезды» г. Красноярска

Figure 6. Rating of competitiveness of 3-star hotels in Krasnoyarsk

Выводы и дискуссионные вопросы. В настоящее время, несмотря на кризисные явления, гостиничный бизнес развивается стремительными темпами. С каждым годом возрастает конкуренция на данном рынке. В основе конкурентоспособности лежит сочетание цены и качества. При одинаково высокой репутации гостиничное предприятие конкурентоспособно только при условии, что его цены не превышают цен конкурентов.

Подводя итоги анализа гостиниц категории «3 звезды» г. Красноярска, можно сделать следующие выводы.

Наиболее важные конкурентные преимущества гостиничных предприятий характеризуются состоянием материально-технической базы, месторасположением предприятия, уровнем качества обслуживания, спектром предоставляемых услуг, узнаваемостью торговой марки, уровнем стоимости услуг и др. Для оценки конкурентоспособности средств размещения авторами была выбрана и адаптирована методика «Анализ четырех показателей», на основе которой были выявлены гостиницы с наибольшим уровнем конкурентоспособности на гостиничном рынке г. Красноярска: «Снежная Сова», «Красноярск», «Іاbis Красноярск Центр». Данные гостиницы отвечают всем требованиям конкурентоспособности. 


\section{Библиографический список}

1. Степанов, Л. В. Конкурентоспособность предприятия в условиях рынка : монография [Текст] / Л. В. Степанов. - Воронеж : Научная книга, 2010. - 203 с.

2. Баумгартен, Л. В. Анализ методов определения конкурентоспособности предприятий [Текст] / Л. В. Баумгартен // Маркетинг в России и за рубежом. - 2012. №5. - С. 34-36.

3. Яброва, О. А. Научно-методические подходы к оценке качества гостиничных услуг [Текст]/ О. А. Яброва, Т. Л. Камоза, Е. В. Шешегова, Т. Н. Сафронова // Экономика и предпринимательство. - 2021. - № 6. - С. 812-818.

4. Официальный сайт Турпортал Красноярск. [Электронный ресурс]. - Режим доступа : http://welcomekrsk.ru/ (дата обращения: 11.09.2021).

5. Управление Федеральной службы государственной статистики по Красноярскому краю Республике Хакасия и Республике Тыва (Красноярскстат) [Электронный ресурс]: офиц. сайт. Красноярск, 2019. URL: http://krasstat.gks.ru/ (дата обращения: 10.09.2021).

6. Официальный сайт системы интернет-бронирования отелей Booking.com. [Электронный pecypc]. - Режим доступа : https://www.booking.com (дата обращения: 11.08.2021).

7. Сафронова, Т. Н. Современные тенденции и проблемы развития гостиничного рынка Красноярского края [Текст] / Т. Н. Сафронова, О. А. Яброва, Т. Л. Камоза, О. М. Евтухова // Наука Красноярья. - 2019. - Т. 8. - №. 3. - C 82-97. DOI: 10.12731/20707568-2019-3-82-97.

\section{References}

1. Stepanov, L. V. (2010). Competitiveness of the enterprise in market conditions. Voronezh. Scientific Book. 203.

2. Baumgarten, L. V. (2012). Analysis of methods for determining the competitiveness of enterprises. Marketing in Russia and abroad. 5. 34-36.

3. Yabrova, O. A., Kamoza, T. L., Sheshegova, E. V. \& Safronova, T. N. (2021). Scientific and methodological approaches to assessing the quality of hotel services. Economics and Entrepreneurship. 6. 812-818.

4. The official website of the Krasnoyarsk Travel Portal. [electronic resource]. Access mode : http://welcomekrsk.ru / (accessed: 11.09.2021).

5. Department of the Federal State Statistics Service for the Krasnoyarsk Territory of the Republic of Khakassia and the Republic of Tyva (Krasnoyarsk State Statistics Service) [Electronic resource]: ofic. website. Krasnoyarsk, 2019. URL: http://krasstat.gks.ru / (accessed: 09/10/2021).

6. Official website of the online hotel booking system Booking.com . [electronic resource]. Access mode : https://www.booking.com (accessed: 08/11/2021).

7. Safronova, T. N., Yabrova, O. A., Kamoza, T. L. \& Evtukhova. O. M. (2019). Modern trends and problems of development of the hotel market of the Krasnoyarsk Territory. Science of Krasnoyarsk. Vol. 8. No. 3. 82-97. DOI: 10.12731/2070-7568-2019-382-97. 